\title{
A GESTÃO ESCOLAR COMO SUBSÍDIO AO DIREITO À EDUCAÇÃO: uma articulação a partir da noção de função social da escola
}

\author{
CATARINA DE ALMEIDA SANTOS \\ Departamento de Planejamento e Administração - UNB. ORCID: 0000-0003-1864-4608. \\ E-mail: catarinasantos@unb.br \\ DANIELLE XÁBREGAS PAMPLONA NOGUEIRA \\ Departamento de Planejamento e Administração - UnB. ORCID: 0000-0001-8500-0402. \\ E-mail: daniellen@unb.br

\section{MARCELLO FERREIRA} \\ Instituto de Física - UnB. ORCID: 0000-0003-4945-3169. E-mail: marcellof@unb.br
}




\section{A GESTÃo ESCOLAR COMO SUBSÍDIO AO DIREITO À EDUCAÇÃO: uma articulação a partir da noção de função social da escola}

A educação, como saber historicamente acumulado, é também apropriação da cultura de um povo. Ela é a responsável por fazer com que as novas gerações assimilem "as experiências, os conhecimentos e os valores legados pelas gerações precedentes, [sendo assim], é fenômeno inerente ao próprio homem e que o acompanha durante toda a sua história" (PARO, 2008, p. 105).

A sociedade moderna, em sua complexidade, traz consigo o acúmulo de saberes produzidos historicamente, que se renova com impressionante velocidade e dinamicidade, requerendo a existência de instituições responsáveis pelo processo educativo. A escola, ressalta Paro (2008), destaca-se entre elas, tendo como especificidade a transmissão do saber de forma sistemática e organizada.

Segundo a Organização das Nações Unidas (ONU, 2009), a educação é um direito humano universal e deve visar à plena expansão da personalidade humana e ao reforço dos direitos e das liberdades fundamentais. No Brasil, em caráter estrutural, a Constituição de 1988 consentiu a educação como um direito social, a que todos, sem distinção, devem ter acesso, delegando ao Estado e à família garanti-lo, em cooperação com a sociedade, para o alcance da sua tríplice função: o pleno desenvolvimento da pessoa, o seu preparo para o exercício da cidadania e a sua qualificação para o trabalho. Já operacionalmente, a Lei de Diretrizes de Bases da Educação Nacional (BRASIL, 1996, art. $1^{\text {o }}$ ) define a educação numa perspectiva ampliada, asseverando que deva abranger "os processos formativos que se desenvolvem na vida familiar, na convivência humana, no trabalho, nas instituições de ensino e pesquisa, nos movimentos sociais e organizações da sociedade civil e nas manifestações culturais".

Fazer com que essa perspectiva de educação se concretize sempre careceu - e certamente ainda carecerá - de muita luta, com ações e campanhas que questionem os modos de ser e de operar das políticas públicas e das dinâmicas sociais. Como disse Anísio Teixeira, lá em 1935, ao debater os entraves enfrentados para implementar o que foi aprovado na Constituição de 1934, "a mentalidade dos fazedores de orçamento, geralmente homens que reputam o ensino obra eminentemente supérflua, criará todos os sofismas para demonstrar a impossibilidade material de se obedecer à Constituição" (TEIXEIRA, 2007, p. 219). Essa afirmação, embora quase noventenária, é lamentavelmente ainda atual. 
A gestão da escola ${ }^{1}$, como organização complexa (TRAGTENBERG, 2018), é um dos mais estatutários dispositivos da garantia do acesso à educação. Segundo Paro (2008, p. 18), “a administração é a utilização racional de recursos para [a] realização de fins determinados", o que implica que ela deva mediar recursos e demandas, em vistas do alcance de sua função social.

Sendo a formação o objetivo central da escola, o projeto pedagógico deve ser a razão da ação administrativo no interior dessa instituição. Nesse sentido, o autor defende que qualquer diretor escolar deve, antes de tudo, ser um educador; defende, ainda, que gestão administrativa e pedagógica, no âmbito escolar, sejam indissociáveis, pois, no campo da gestão escolar, toda prática pedagógica está impregnada do administrativo, assim como o administrativo é potencialmente pedagógico.

No Manifesto dos Pioneiros da Educação Nova de 1932 (MANIFESTO, 2006), os pioneiros já defendiam a formação ampla dos educadores e gestores educacionais. Um educador que trabathe cientificamente nesse terreno, defendia o Manifesto, deve estar decisivamente interessado na determinação dos fins de educação e imbuído dos meios de realizá-los. Nessa perspectiva, o gestor precisa ser, antes de tudo, um educador e, como tal, alguém capaz de compreender a realidade para além dos muros da escola. Assim, para os signatários do Manifesto, dentre eles, Anísio Teixeira,

O físico e o químico não terão necessidade de saber o que está e se passa além da janela de seu laboratório. Mas o educador, não, ele tem necessidade de uma cultura múltipla e bem diversa; ele deve ter o conhecimento dos homens e da sociedade em cada uma de suas fases, para perceber, inclusive a posição que tem a escola, e a função que representa, na diversidade e pluralidade das forças sociais que cooperam na obra da civilização (MANIFESTO, 2006).

Separar a gestão pedagógica da gestão administrativa - ou o gestor do educador - é incorrer no amadorismo pedagógico ou no empirismo grosseiro de que os pioneiros falavam, pois isso implicaria considerar que a escola pudesse ser administrada por quem não entende dos princípios e das especificidades da educação. Essa instituição escolar se assenta em princípios da democracia, da autonomia e da liberdade e deve ser plural, imiscuída em cultura e com radical envergadura e

\footnotetext{
1 Neste texto, por conveniência semântica e pela restrição do escopo dos matizes conceituais que pretendemos acessar, tomamos gestão escolar e administração escolar como sinônimos. Sabe-se, no entanto, que, no campo dos estudos organizacionais, a perspectiva de administração escolar é eminentemente técnica e operacional, enquanto a ideia de gestão escolar vincula-se a uma perspectiva diretiva mais sistêmica, atinente às políticas, às diretrizes educacionais, à gestão de sistemas de ensino e escolas, considerando a autonomia e a necessidade de processos participativos.
}

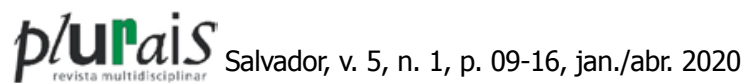


compromisso social. Seu papel é o de garantir, de forma organizada e sistematizada, a mais difícil das educações: aquela para viver de forma livre e democrática. Como disse Anísio,

Há educação e educação. Há educação que é treino, que é domesticação. E há educação que é formação do homem livre e sadio. Há educação para alguns, há educação para muitos e há educação para todos. A democracia é o regime da mais difícil das educações, a educação pela qual o homem, todos os homens e todas as mulheres aprendem a ser livres, bons e capazes (TEIXEIRA, 2009, p. 107).

Garantir o direito à educação é formar para a democracia, regime que, segundo Teixeira, dela depende fundamentalmente, pois só há democracia se tivermos uma educação capaz de "fazer do filho do homem - graças ao seu incomparável poder de aprendizagem - não um bicho ensinado, mas um homem" (TEIXEIRA, 2009, p. 107).

Assim, pensar a gestão como uma das dimensões do processo educativo, voltada para garantia do direito à educação, implica em envolver o conjunto dos sujeitos das comunidades escolar e local na tomada de decisão, em problematizar políticas e diretrizes internas e externas de cunho não democrático e que não sirvam para o alcance da educação em que todos os homens e todas as mulheres aprendem a ser livres, bons e capazes.

As demandas externas advindas de tomadores de decisões, que reputam o ensino, especialmente para a maioria da população, obra eminentemente supérflua, costumam ser contrárias ao alcance dessa educação com referência social, não somente no Brasil, mas em praticamente todos os países do globo. Daine Ravich² (2011), no livro "Vida e morte do grande sistema escolar americano: como os testes padronizados e o modelo de mercado ameaçam a educação", analisa os efeitos dos testes padronizados e do modelo de mercado no sistema americano. Para a autora, os testes, definidos por homens de negócio e não por quem entende de educação, estão colocando o sistema educativo americano em risco, tendo em vista que não está sendo garantido a formação dos estudantes, o que vem desencadeando e agudizando processos de segregação e exclusão.

Para Ravitch (2011, p. 251), "os fundamentos de uma boa educação serão encontrados na sala de aula, em casa, na comunidade e na cultura, mas os reformadores empresariais do nosso

2 Diane Silvers Ravitch: Is a historian of education, an educational policy analyst, and a research professor at New York University's Steinhardt School of Culture, Education, and Human Development.

\section{plupais


tempo continuam a procurar por atalhos e respostas rápidas" (RAVITCH, 2011, p. 251). Ainda segundo a autora,

\begin{abstract}
As nossas escolas não irão melhorar se os políticos que nos governam se meterem no território pedagógico e tomarem decisões que deveriam ser feitas por educadores profissionais. O Congresso e os legisladores estaduais não deveriam dizer aos professores como ensinar, tanto quanto eles não devem dizer aos cirurgiões como realizar operações. Tampouco o currículo das escolas deveria ser submetido a negociações políticas entre pessoas que não possuem conhecimento sobre o ensino. A pedagogia - ou seja, como ensinar - é domínio profissional dos professores. O currículo - ou seja, o que ensinardeveria ser determinado por educadores profissionais e acadêmicos, após a devida deliberação pública, agindo com a autoridade neles investida pelas escolas, distritos e Estados (RAVITCH, 2011, p. 251).
\end{abstract}

Os processos de organização, planejamento e avaliação das diversas atividades que fazem parte do cotidiano das instituições escolares e da administração educacional e escolar precisam ser pautados por ações que garantam o direito à educação. A função social da escola vai muito além de desenvolver capacidades nos estudantes para responder o que os testes mensuram, notadamente os progressos dos estudantes em leitura e em matemática, pois esses testes não dão conta de estabelecer indicadores para o que mais importa na educação: "a habilidade de um estudante de encontrar explicações alternativas, levantar dúvidas, buscar o conhecimento por conta própria e pensar de forma diferente" (RAVITCH, 2011, p. 252).

O que Ravitch, assim como muitos outros educadores, coloca na agenda de debate na atualidade é o que Teixeira já apontava, em 1935, ao refletir e apontar os problemas da educação brasileira à época. Para esse autor, o primeiro erro no campo da educação seroa tomar as causas pelos efeitos e os efeitos pelas causas. Assim, afirmou que,

Desde que se iniciou a civilização democrática e industrial dos nossos tempos, os índices de alfabetização foram-se tonando extraordinariamente significativos do estado de progresso de um povo, por isso que a generalização da leitura e da escrita se tornou indispensável a generalização de modos especiais de vida e de trabalho. Pois bem. Como não somos muito favorecidos por aqueles índices, facilmente nos convencemos de que o necessário é conquistá-los de qualquer jeito, para nos tornarmos de pronto civilizados. Ora, a verdade é bem outra. 
Precisamos é daquela civilização, para que os índices, de longe, surjam por si mesmos (TEIXEIRA, 2007, p. 41).

A defesa de Teixeira (2007, p. 84), de Ravitch e que é também a nossa, é a de que é preciso ter na escola muito mais "do que o ensino a toque de caixa de leitura, escrita e contas". É preciso fazer com que nossos estudantes tenham oportunidades de ter uma vida melhor.

O que devem desejar os educandos brasileiros é que a escola não falhe a sua missão; é que a escola forme a inteligência e forme o caráter. Mas, para tanto, urge que preparemos o ambiente, que o prédio escolar e as suas instalações atendam, pelo menos, aos padrões médios da vida civilizada, e que o magistério tenha a educação, a visão e o preparo necessários a quem não vai apenas ser a máquina de ensinar intensivamente a ler, a escrever e a contar, mas o mestre da arte difícil de bem viver (TEIXEIRA, 2007, p. 85).

A tríplice função da educação, definida no art. 205 de Constituição de 1988, nos coloca o desafio de olhar para o estudante como sujeito e garantir seu desenvolvimento a partir da sua especificidade, dentro da pluralidade. Que a escola não o apague, não o anule, não o uniformize ou o invisibilize, garantindo as condições para que suas potencialidades intelectuais, afetivas e psicomotoras sejam desenvolvidas.

Ao mesmo tempo, sendo ele um sujeito social, a formação para a cidadania, parte constitutiva do direito a educação, não é a formatação das mentes, o controle dos corpos para que sejam economicamente úteis e socialmente dóceis, nem a obediência pela imposição do medo, mas a construção do respeito. Isso só é viável quando se convive com o diverso, quando não se anulam as diferenças e quando se debate com respeito as questões postas na sociedade, como as questões de gênero, raça e sexualidade. Não é possível formar para a cidadania quando se elimina da escola a formação que combata o racismo, o machismo, sexíssimo, feminicídio, a homofobia, o patriarcado e todas as formas de violência e discriminação. Essas preocupações devem integrar o leme da gestão escolar e operar para que jamais entremos em um mundo distópico como esse, que escolhe entre formar para a racionalidade substantiva ou formar para a racionalidade técnica. São inúmeros os cidadãos - e, infelizmente, também os líderes políticos - que ignoram a relação entre ciência, tecnologia e sociedade. Espera-se que mais deles não sejam constituídos pela indiferença ou pela ação deliberadamente neoliberal da escola. Nada poderia substituir o ambiente escolar tradicional; trata-se de um valor civilizatório, uma conquista moderna, cuja perda se faria lamentar profunda-

\section{plurais}


mente, pois já não podemos reconhecer em nosso meio tantos daqueles espaços comunitários que cumpriam o papel de socialização de crianças, no sentido mais elevado de transmissão de práticas de tolerância e de construção de acordos.

A formação para o trabalho, terceira haste do tripé, não é a formação para conformação ao modus operandi da atual forma de organização social, em que as relações sociais se dão pela exploração de uma parte da população sobre a outra. A formação para o trabalho, constitutiva do direito à educação, precisa ser para a transformação das relações de trabalho em que os trabalhadores sejam sujeitos e não objetos ou meios de produção. A educação deve contribuir, como aponta Vitor Paro (2008), para a transformação social a medida em que servir de instrumento dos grupos sociais dominados, em seu esforço de superação da sociedade de classe. Esta é a indução, a tessitura e a conformação social que somente se pode viabilizar por meio de uma escola democrática, plural, defensora dos direitos humanos e das garantias de liberdade e cônscia do seu papel singular de regulação entre do projeto político do Estado ao indivíduo e o projeto desse mesmo indivíduo em si e para si. A gestão escolar é, pois, a vereda entre o que se está determinado para a educação escolar como função social e dimensão para a garantia do direito à educação.

\section{REFERÊNCIAS}

BRASIL. Constituição (1988). Constituição da República Federativa do Brasil. Brasília, DF: Senado Federal, 1988.

BRASIL. Lei n' 9.394, de 20 de dezembro de 1996. Estabelece as diretrizes e bases da educação nacional. Brasília, DF: Presidência da República, [1996]. Disponível em: http://www. planalto.gov.br/ccivil 03/leis/19394.htm. Acesso em: 715 de maio de 202019.

O MANIFESTO dos Pioneiros da Educação Nova (1932). Revista HISTEDBR On-line, Campinas, n. especial, p. 188-204, ago. 2006. Disponível em: http://www.histedbr.fe.unicamp.br/revista/edicoes/22e/doc1_22e.pdf. Acesso em: 8 maio 2020.

ONU. Declaração Universal dos Direitos Humanos. 2009. Disponível em: https://nacoesunidas.org/wp-content/uploads/2018/10/DUDH.pdf. Acesso em: 7 maio 2020.

PARO, V. H. Administração escolar: introdução crítica. 15. ed. São Paulo: Cortez, 2008. 
RAVITCH, D. Vida e morte do grande sistema escolar americano: como os testes padronizados e o modelo de mercado ameaçam a educação. Porto Alegre: Sulina, 2011.

TEIXEIRA, A. S. Educação é um direito. 4 ed. Rio de Janeiro: Editora da UFRJ, 2009.

TEIXEIRA, A. S. Educação não é um privilégio. São Paulo: Companhia Editora Nacional, 1977.

TEIXEIRA, A. S. Educação para a democracia: introdução a administração educacional. $3^{\text {a }}$ Edição. Rio de Janeiro: Editora da UFRJ, 2007.

TRAGTENBERG, M. A Escola cmo Organização Complexa. Educ. Soc., Campinas, v. 39, n. 142, p. 183-202, jan. 2018.

Enviado em: 30 de março de 2020.

Inserido em: 20 de abril de 2020.

Esta obra está licenciada com uma Licença Creative Commons Atribuição 4.0 Internacional. 